\title{
Olivier Landron, La vie chrétienne dans les prisons de France au $\mathrm{XX}^{\mathrm{e}}$ siècle
}

Paris, Éditions du Cerf, coll. «L'histoire à vif », 2011, 684 p.

\section{Céline Béraud}

\section{(2) OpenEdition}

\section{Journals}

Édition électronique

URL : http://journals.openedition.org/assr/24639

DOI : $10.4000 /$ assr.24639

ISSN : $1777-5825$

Éditeur

Éditions de l'EHESS

Édition imprimée

Date de publication : 30 décembre 2012

Pagination : 223

ISSN : 0335-5985

Référence électronique

Céline Béraud, "Olivier Landron, La vie chrétienne dans les prisons de France au XXe siècle », Archives de sciences sociales des religions [En ligne], 160 | octobre-décembre 2012, mis en ligne le 18 mars

2013, consulté le 21 septembre 2020. URL : http://journals.openedition.org/assr/24639; DOI : https:// doi.org/10.4000/assr.24639

Ce document a été généré automatiquement le 21 septembre 2020.

(c) Archives de sciences sociales des religions 


\section{Olivier Landron, La vie chrétienne dans les prisons de France au $\mathrm{XX}^{\mathrm{e}}$ siècle}

Paris, Éditions du Cerf, coll. «L'histoire à vif », 2011, 684 p.

\section{Céline Béraud}

\section{RÉFÉRENCE}

Olivier Landron, La vie chrétienne dans les prisons de France au XXe siècle, Paris, Éditions du Cerf, coll. «L'histoire à vif », 2011, 684 p. 
Olivier Landron est un historien qui n'hésite pas à défricher des terrains encore peu travaillés en France tels que les communautés nouvelles (Les communautés nouvelles. Nouveaux visages du catholicisme français, Le Cerf, 2004) ou les rapports entre l'Église catholique et l'environnement (Le catholicisme vert. Histoires des relations entre l'Église et la nature au $\mathrm{XX}^{e}$ siècle, Le Cerf, 2008). Avec le présent ouvrage, il offre une somme conséquente sur la religion en prison au cours du siècle dernier. Sur la période contemporaine, on ne disposait jusqu'à présent que de quelques contributions, certes fort stimulantes, mais peu nombreuses et surtout centrées sur le XIX ${ }^{\mathrm{e}}$ siècle: de Jacques-Guy Petit, Philippe Artières et Claude Langlois (qui ne figure pas parmi les références

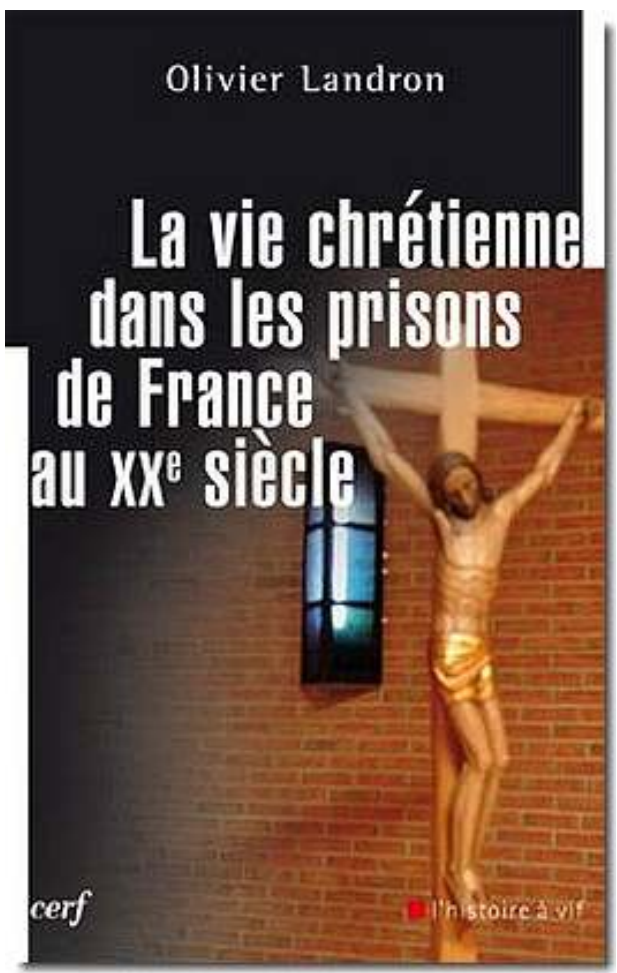
bibliographiques). L'auteur se propose de retracer l'histoire des relations entre le catholicisme et le monde carcéral. L'héritage religieux de la pénitentiaire est important: "Pour la III République, pourtant laïque, la peine est d'abord une pénitence: un terme ô combien religieux» (p.10). Plus précisément, l'historien s'intéresse aux modalités d'engagement des chrétiens au sein des prisons françaises.

Depuis le $\mathrm{XIX}^{\mathrm{e}}$ siècle, la sanction pénale est pensée en termes religieux. Ainsi, le détenu doit se repentir, s'amender. Comme l'écrit le juriste Maurice Cusson (cité p. 561), «Le vocabulaire du confessionnal fait son entrée... en prison.» En 1924 encore, une circulaire dispose que les détenus doivent sous peine de sanctions disciplinaires assister régulièrement aux offices de leur culte s'ils en ont déclaré un à leur arrivée (choix qu'ils doivent réitérer au début de chaque trimestre). Pourtant, les prisons comme d'autres institutions publiques connaissent une vague de laïcisation (certes incomplète) au début $\mathrm{du} \mathrm{xx}^{\mathrm{e}}$ siècle. Les religieuses sont expulsées des différents établissements où elles étaient présentes, à l'exception de Saint-Lazare et du Dépôt de la Préfecture de Police de Paris. Les aumôniers perdent pour un temps leur rémunération (deux décrets de 1931 leur permettront de recevoir des indemnités) et leur suppression est même discutée en 1911. Ils se voient interdire de prodiguer une instruction religieuse aux détenus mineurs. Par un décret du 19 janvier 1923, leur rôle est précisé et strictement encadré : ils ne peuvent visiter que les détenus qui en ont fait la demande, le nombre de ces visites est limité dans la semaine. La circulaire du 25 février 1926 interdit aux détenus d'interrompre leur travail pour s'entretenir avec un aumônier. "Suite à la Séparation [...], les nouveaux aumôniers apparaissent plus que jamais comme des hommes du dehors, étrangers à l'administration pénitentiaire » (p.119), en conclut Olivier Landron. Le Père Marty dénonce au début des années 1940 le fait que la messe ne soit pas célébrée dans certains établissements pénitentiaires (à Valence aucune célébration eucharistique n'a lieu entre 1900 et 1942), du fait de l'opposition du 
gardien-chef. Les aumôniers se plaignent de l'anticléricalisme qui règne dans les prisons dans la première moitié $\mathrm{du} \mathrm{xx}^{\mathrm{e}}$ siècle, dont les surveillants seraient le principal vecteur.

Très minutieusement, l'auteur rend compte successivement de la position des différents acteurs: les autorités catholiques (papes et plus tardivement évêques de France); les prêtres, religieux et religieuses «à l'écoute des détenus " principalement comme aumôniers; la nébuleuse des associations qui agissent sur différents plans (aide matérielle aux indigents apportée notamment par le Secours Catholique, visites avec l'Æuvre de la Visite des Détenus dans les Prisons (OVDP) qui devient en 1992 Association Nationale des Visiteurs de Prison (ANVP), correspondance avec le Courrier de Bovet, enseignement avec Auxilia, accueil des sortants et aide à leur réinsertion, mais également regard critique sur la politique pénitentiaire), associations à l'identité confessionnelle plus ou moins affichée (la tendance étant à la sécularisation) et aux liens plus ou moins étroits avec l'Aumônerie catholique. Pour ce faire, le nombre d'archives dépouillées est considérable. L'historien s'intéresse aussi, mais de manière beaucoup plus impressionniste, à quelques figures de catholiques « au cœur du système judiciaire et pénitentiaire » (dont Pierre Cannat, qui fut un très proche collaborateur de Paul Amor). Enfin, il revient sur quelques conversions, qui ont pour point commun d'avoir fait l'objet de témoignages.

D'un point de vue chronologique, la Seconde Guerre mondiale marque une rupture tant du point de vue de l'administration pénitentiaire (avec en 1945 la Réforme Amor) que de celui du catholicisme (avec la création la même année de l'Aumônerie générale des prisons).

5 Lors de la réforme Amor, le service social des prisons est créé et l'accent est mis sur le « reclassement » des détenus. Un statut est conféré aux visiteurs de prison, dont l'accès à la détention se trouve cependant réduit (ils ne peuvent plus aller en cellules). Le rôle des aumôniers est considéré de manière plus positive. Leur périmètre d'action se trouve précisé dans l'ordonnance du 6 février 1947 : ils ont « pour mission de célébrer les offices religieux, d'administrer les sacrements et d'apporter aux détenus les secours de leur religion respective en vue de les aider dans leurs efforts de redressement "; ils se voient accorder le droit de célébrer un office en dehors des dimanches et jours de fête; ils peuvent constituer une bibliothèque d'ouvrages religieux. Leur statut est consolidé par le décret du 23 février 1959, en application du Code de Procédure pénale de 1958. L'article D. 437 dispose qu'ils peuvent s'entretenir aussi souvent qu'ils le souhaitent avec les détenus de leur culte et qu'aucune sanction ne peut limiter ce droit. Ces entretiens ont lieu en dehors de la présence d'un surveillant dans un parloir, un bureau ou en cellule. Leur correspondance avec les détenus se fait librement et sous pli fermé, conformément à l'article D. 438.

6 À la demande des cardinaux et archevêques de France, Mgr Rodhain (qui crée également le Secours Catholique), assisté de Céline Lhotte (particulièrement investie dans l'organisation des congrès nationaux), fonde l'Aumônerie générale des prisons (qu'il dirigera jusqu'à sa mort en 1977), dans le prolongement des nombreuses initiatives prises par le Père François Marty au début des années 1940. En 1955 et en 1965, des réformes viennent affiner cette structure nationale et centralisée. Au milieu des années 1960, un peu en manque de projet pastoral, l'Aumônerie générale pense son rôle au-delà du seul exercice du culte. Elle souhaite s'inscrire dans la division du travail carcéral, en interaction avec les magistrats, les psychologues, les éducateurs. Oliver 
Landron décrit le malaise des aumôniers (vieillissants, peu formés, exerçant rarement à temps complet et fréquemment renouvelés) au cours des années 1960-1970, isolés, voire marginalisés, au sein des diocèses, disqualifiés par le peu d'intérêt que suscite le monde carcéral dans l'Église. Céline Lhotte a pu écrire que jusqu'à la Seconde Guerre mondiale les évêques « considéraient volontiers les aumôniers de prison comme des postes de fin de carrière pour prêtres fatigués." Tout au long de la période étudiée, l'auteur considère qu'à quelques exceptions près la question carcérale ne s'est jamais trouvée au cœur des préoccupations de l'épiscopat français.

7 Deux circulaires de 1988 autorisent les aumôniers à être assistés par des auxiliaires bénévoles (qui ne peuvent avoir des entretiens individuels avec les détenus). Les conditions de la nomination des aumôniers et de leurs auxiliaires sont précisées par deux circulaires du 24 janvier 1994. Au même moment, la composition interne de l'aumônerie catholique se transforme. On passe de la figure du prêtre seul en activité (encore très largement majoritaire au milieu des années 1980) à un fonctionnement en équipe. Les religieuses (la plus connue étant Isabelle Le Bourgeois) et les laïcs sont de plus en plus nombreux à être recrutés. C'est également le cas des diacres permanents. Le premier aumônier général non prêtre est le diacre Jean-Louis Reymondier, nommé à ce poste en 2004. En 2006, un aumônier catholique sur deux est un laïc.

Entre les différents acteurs religieux et non religieux du monde carcéral se nouent des interactions variées, changeantes au cours du temps. Ainsi, les rapports entre visiteurs et assistantes sociales se tendent à partir des années 1970 (alors que ces dernières sont moins souvent catholiques). En pleine « crise catholique », les membres de l'OVDP sont volontiers critiques par rapport à certains aumôniers qui privilégient les débats avec les détenus et refusent parfois même de dire la messe. Des tensions liées à la pluralité interne du catholicisme français apparaissent également à la fin des années 1980, lorsque des groupes charismatiques tentent de s'implanter dans des établissements pénitentiaires «avec ou sans la complicité des aumôneries» (p.157), comme la Fraternité du Bon Larron fondée par le Père Aubry (lui-même aumônier à Bois-d'Arcy).

9 La présence des différents intervenants catholiques est parfois encouragée par l'administration pénitentiaire, souvent simplement tolérée. Quant à eux, les acteurs religieux se montrent plus ou moins enclins à la critique de l'institution carcérale. Mgr Rodhain apparaît très lié à l'administration pénitentiaire, ce qui lui est reproché par certains de ses aumôniers. Cette position de type attestataire qui est également celle de son adjoint, le Père Rousset, permet notamment d'expliquer la distance prise par rapport au Groupe d'information sur les prisons (GIP) : «Pour beaucoup de chrétiens, catholiques comme protestants, le groupe de Michel Foucault avait le grand tort de vouloir établir une cassure entre les Églises et l'administration pénitentiaire qui, pourtant, avaient vécu entre elles une forme d'alliance depuis le xix siècle. [...] D'après Philippe Artières, ils (les aumôniers) auraient été incités à soutenir cette dernière (l'administration pénitentiaire) afin de conserver un pouvoir dans le monde carcéral qui était de plus en plus contesté par la forte augmentation des travailleurs sociaux " (p. 550). Les prises de paroles d'aumôniers de terrain ne manquent pas pour autant. Landron dresse ainsi le portrait de plusieurs figures (dont la plus emblématique est certainement le Père Niaussat), qui n'ont pas hésité à dénoncer dans des ouvragestémoignages les conditions d'incarcération, le régime des sanctions et des peines (la peine de mort tout spécialement), voire à s'opposer ouvertement à l'administration pénitentiaire. 
10 À l'aube du xxI siècle, la présence catholique est encore importante dans les prisons françaises. Le nombre d'aumôniers est même en hausse. Entre 1991 et 1995, il passe de deux cent trente à trois cent soixante. Il atteint 600 en 2012. Les Sœurs de Marie-Joseph et de la Miséricorde sont encore présentes à la maison d'arrêt des femmes de FleuryMérogis, au centre pénitentiaire de Rennes, ainsi qu'au Dépôt à Paris. Des Sœurs de Béthanie, dont la congrégation est vieillissante, visitent plusieurs fois par an les détenues de Rennes. Quant au Secours Catholique, il demeure l'une des associations les plus actives dans les prisons françaises. En conclusion, l'auteur lui-même s'interroge : «Comment peut-on expliquer que le christianisme et plus spécifiquement le catholicisme aient conservé en France, au xxe siècle, un rôle influent dans l'univers carcéral, ancré dans une société profondément sécularisée? » (p. 658). Cette question, posée un peu tard, aurait pu constituer la problématique de l'ouvrage.

11 On peut aussi regretter que le titre du livre ne corresponde pas tout à fait à son contenu. Ainsi, il est surtout question du catholicisme et non pas de la présence chrétienne dans son ensemble. Le protestantisme est principalement abordé au prisme de l'œcuménisme, plus précisément de celui des associations nées en milieu protestant, mais travaillant en collaboration avec des catholiques (dont les plus connues sont certainement la Cimade et l'action des chrétiens pour l'abolition de la torture (ACAT). Seules trois pages (chap. 9) sont consacrées aux rapports entre aumôniers catholiques et protestants. Quelques actions communes sont mentionnées : en 1979 contre la peine de mort, en 1980 contre le projet de loi "Sécurité et liberté », en 1988 pour sensibiliser les parlementaires aux conditions de détention. Quant aux orthodoxes dont le nombre a crû au cours des dix dernières années, ils disposent d'un aumônier national depuis l'été 2010 mais encore de très peu d'aumôniers dans les établissements. Globalement, les analyses sont rapides sur la fin de période, pourtant riches en changements : effets produits par la présence d'un nombre croissant de laïcs parmi les aumôniers (dont une part importante de femmes); défi que représente la pluralité religieuse et tout particulièrement la présence de l'islam dans l'espace carcéral. Autre point, le propos est moins centré sur la vie chrétienne, c'est-à-dire sur des pratiques, que sur des institutions, leurs représentants et leurs discours. Les quelques conversions décrites en fin d'ouvrage ne suffisent pas à donner à voir la vie religieuse des détenus. Ce livre a donc également le mérite d'ouvrir la voie à de nouvelles recherches sur la religion en prison. 